\title{
Reactive-Sputtered Prepared Tin Oxide Thin Film as an Electron Transport Layer for Planar Perovskite Solar Cells
}

\author{
Wenhai Sun ${ }^{1}$, Shuo Wang ${ }^{1}$, Shina $\mathrm{Li}^{1}{ }^{1}$, Xu Miao ${ }^{1}$, Yu Zhu ${ }^{1}$, Chen Du ${ }^{1}$, Ruixin Ma ${ }^{1,2, *}$ (D) and \\ Chengyan Wang ${ }^{1,3, *}$ \\ 1 School of Metallurgical and Ecological Engineering, University of Science and Technology Beijing, \\ Beijing 100083, China; g20178246@xs.ustb.edu.cn (W.S.); b20180139@xs.ustb.edu.cn (S.W.); \\ s20180252@xs.ustb.edu.cn (S.L.); g20178237@xs.ustb.edu.cn (X.M.); g20178277@xs.ustb.edu.cn (Y.Z.); \\ s20170220@xs.ustb.edu.cn (C.D.) \\ 2 Beijing Key Laboratory of Special Melting and Preparation of High-End Metal Materials, \\ University of Science and Technology Beijing, Beijing 100083, China \\ 3 Beijing Key Laboratory of Rare and Precious Metals Green Recycling and Extraction, \\ University of Science and Technology Beijing, Beijing 100083, China \\ * Correspondence: maruixin@ustb.edu.cn (R.M.); q1590q@163.com (C.W.); Tel.: +86-010-623-33170 (R.M.)
}

Received: 21 March 2019; Accepted: 6 May 2019; Published: 14 May 2019

\begin{abstract}
Currently, tin oxide $\left(\mathrm{SnO}_{2}\right)$ is a highly sought-after semiconductor material used in perovskite solar cells (PSCs) because of its good transmittance, the appropriate energy level, high electron mobility, high conductivity, ideal band gap and excellent chemical stability. In this study, $\mathrm{SnO}_{2}$ film was successfully prepared by radio frequency reactive magnetron sputtering (RS) under room temperature conditions. The obtained $\mathrm{SnO}_{2}$ thin films not only exhibited high transmittance in the visible region as well as the pure phase, but also had a suitable energy band structure and lower surface roughness than FTO $\left(\mathrm{SnO}_{2}: \mathrm{F}\right)$ glass substrate, which contributes to the improvement of the adjacent interface morphology. The $\mathrm{SnO}_{2}$ films prepared by reactive sputtering could effectively suppress carrier recombination and act as an electron transport layer. Moreover, the maximum efficiency of the device based on reactive sputtering of $\mathrm{SnO}_{2}$ as the electron transport layer (ETL) for planar perovskite solar cells (PSCs) was $14.63 \%$. This study mainly described the preparation of $\mathrm{SnO}_{2}$ by reactive sputtering under room temperature conditions.
\end{abstract}

Keywords: $\mathrm{SnO}_{2}$ thin films; reactive magnetron sputtering; electron transport layer

\section{Introduction}

Perovskite solar cells (PSCs) are developing rapidly, and the power conversion efficiency (PCE) of these devices have increased from $3.8 \%$ [1] to over $20 \%$ [2] in a very short time, and continues to be optimized [3]. In the past, mesoporous perovskite has always been a classical structure with high efficiency [4]. At present, the efficiency of the device based on this classic structure has reached 23.2\% [3]. Titanium oxide $\left(\mathrm{TiO}_{2}\right)$ is a widely-used electron transport material in perovskite solar cells, and mesoporous layer $\mathrm{TiO}_{2}$ is the most typical nanostructure. The dense $\mathrm{TiO}_{2}$ acts to transport electron blocking holes, and the function of the porous $\mathrm{TiO}_{2}$ is to improve the uniformity of the spin-coated perovskite film. However, since the preparation of titanium dioxide needs to undergo a high temperature process, has weak optical stability and low mobility, leading to higher production costs and longer energy recovery times [5], its development is greatly limited [6]. On this basis, the fabrication of planar PSCs and electron transport layers has attracted extensive research [7]. Developing new electron transport layer materials, such as $\mathrm{Zn}_{2} \mathrm{SnO}_{4}$ [8], $\mathrm{In}_{2} \mathrm{O}_{3}$ [9], $\mathrm{WO}_{x}$ [10], $\mathrm{ZnO}$ [11], PCBM [12], 
and $\mathrm{SnO}_{2}$ [13] is a way to solve the shortcomings of titanium oxide. Among these materials, the most promising substitution for $\mathrm{TiO}_{2}$ is $\mathrm{SnO}_{2}$, because $\mathrm{SnO}_{2}$ does not require high temperature preparation and has excellent photoelectric properties such as high electron mobility, suitable band gap and band structure, and high transparency [13]. The initial studies of $\mathrm{SnO}_{2}$ in PSCs were almost concurrently carried out in many research teams, such as Dai and co-workers and the Guojia Fang teams [13], who reported an efficiency of $\sim 3.9 \%$ and over $20 \%$ [14], respectively. After that, $\mathrm{SnO}_{2} \mathrm{ETLs}$ attracted more and more attention and made rapid progress [6]. At present, the device with $\mathrm{SnO}_{2}$ as the ETLs has reached $21.52 \%$ efficiency [15], although there is still great potential for further increasing that efficiency [16].

Many methods were attempted to synthesize tin oxide [13]. Ke et al. used air annealing of $\mathrm{SnO}_{2}$ film at $180{ }^{\circ} \mathrm{C}$, made by the low-temperature solution method for $1 \mathrm{~h}$, to realize $17.21 \%$ efficiency in planar perovskite [17]. Hagfeldt and co-workers deposited $\mathrm{SnO}_{2}$ layers by ALD (atomic layer deposition) technology applied to planar PSCs with an efficiency over $18 \%$ and a high voltage of $1.19 \mathrm{~V}$ [18]. In addition, Hagfeldt and co-workers used chemical bath deposition (CBD) and spin coating to obtain $\mathrm{SnO}_{2}$ layers, with the efficiency of the device made by this method being more than $20.7 \%$ and also having better stability performance [13]. Jen and co-workers prepared $\mathrm{SnO}_{2}$ as an electron transport layer by electrochemical deposition and applied it to planar PSCs with an efficiency of $13.88 \%$ [19]. The latter has the advantages of low temperature treatment and no annealing treatment. In summary, the solution method is the main method to prepare $\mathrm{SnO}_{2}$ as an ETL, and the PSCs production efficiency is higher than other methods, but spin coating and annealing limit the application of PSCs commercialization [20]. Moreover, the low deposition rate, being time consuming and high cost of making tin oxide electron transport layer by ALD technology also limit its application for industrialization [21]. On the contrary, radio frequency magnetron sputtering (RS) is a mature technology for low cost industrialization of semiconductor materials [6,22]. RS has played an important role in making electron transport and hole barrier layers in PSCs [23], including improving device performance [24], lowering temperature and reducing costs [25], as well as providing a basis for large-scale and industrialized solar cells that cannot be replaced by other methods [26]. There are a few reports about the application of $\mathrm{SnO}_{2}$ electron transport layer made by magnetron sputtering to planar PSCs [6]. Giulio et al. has prepared $\mathrm{SnO}_{2}$ film by reactive sputtering for application in gas sensors [27]. Qiu et al. used tin oxide prepared by sputtering and obtained very good results in perovskites [28]. In addition, reactive magnetron sputtering can prepare a compound film of a compound ratio by adjusting parameters [29], thereby realizing the controllability of the film and having less restrictions on the substrate [30], and depositing $\mathrm{SnO}_{2}$ on various substrates [30] which is very suitable for large-area uniform coating and industrial production [31]. The radio frequency (RF) sputter-deposited film is relatively denser and flatter, but we should not easily conclude before further studying the two sputtering methods. In addition, since the tin target is a pure metal target, the target is easier to prepare due to the ductility of the metal during preparation, compared to the tin oxide target. Moreover, the tin target requires less excitation energy at the time of sputtering than the tin oxide target because the molecular weight of tin is smaller than the molecular weight of tin oxide. In this paper, the preparation of $\mathrm{SnO}_{2}$ thin film electron transport layer by radio frequency magnetron reactive sputtering at room temperature and its application to planar PSCs was studied. It has been found through research that $\mathrm{SnO}_{2}$ film prepared at room temperature has a smooth surface, good transmittance, a wide band gap, and a suitable energy level position, which makes $\mathrm{SnO}_{2}$ film sputtered at room temperature have good electron transport layer properties. Finally, $\mathrm{SnO}_{2}$ is applied in planar PSCs to obtain an efficiency of $14.63 \%$. This paper provides a simpler and more cost-effective method for the application of $\mathrm{SnO}_{2}$ to PSCs, which is conducive to the promotion and application of large areas. 


\section{Experimental Section}

\subsection{Preparation of $\mathrm{SnO}_{2}$ Film}

At room temperature, $\mathrm{SnO}_{2}$ thin films prepared by radio frequency reactive magnetron sputtering were deposited on FTO $\left(\mathrm{SnO}_{2}: \mathrm{F}\right)$. FTO layers on glass substrates were cleaned with alkaline detergent, acetone, absolute ethanol and deionized water for $15 \mathrm{~min}$. The cleaned substrates were then UV-ozone treated for $15 \mathrm{~min}$ before they were used for sputtering. A $99.99 \%$ pure tin (Sn) target (the target size is $\Phi 50 \times 4 \mathrm{~mm}$ ) was fixed in the vacuum chamber and the FTO glass was fixed on the substrate, with the height between Sn target and FTO substrate being close to $50 \mathrm{~cm}$. The base pressure was pumped to $6 \times 10^{-4} \mathrm{~Pa}$ before any sputtering was carried out. The incoming gas consisted of $99.99 \%$ pure argon (Ar) and $99.99 \%$ pure oxygen $\left(\mathrm{O}_{2}\right)$. The flow rate of argon and oxygen was 9 to 1 . The surface impurities of the FTO glass substrate were cleaned by intermediate frequency cleaning for $10 \mathrm{~min}$, and the target surface impurities were removed by $15 \mathrm{~min}$ pre-sputtering before sputtering. The sputtering power of the $\mathrm{Sn}$ target was $50 \mathrm{~W}$ with the sputtering time being set to 10, 20 and $30 \mathrm{~min}$ (marked as sample RS-10, RS-20, and RS-30). When starting to sputter the tin target, the operating frequency was $13.56 \mathrm{MHz}$ and the waveform was a Sine wave. In addition, the substrate bias was $180 \mathrm{~V}$.

\subsection{Fabrication of Planar Perouskite Solar Cells}

Using a blank FTO $\left(\mathrm{SnO}_{2}: \mathrm{F}\right)$ glass substrate as a comparison, a perovskite layer was deposited by a one-step method, and a prepared perovskite solution $\left(\mathrm{CH}_{3} \mathrm{NH}_{3} \mathrm{I}\right.$ and $\left.\mathrm{PbI}_{2}=1: 1\right)$ was applied to the sample at a rotation speed of $3000 \mathrm{rpm}$ for $30 \mathrm{~s}[32,33]$. The perovskite films were annealed at $100{ }^{\circ} \mathrm{C}$ for $10 \mathrm{~min}$. After cooling to room temperature, $72.3 \mathrm{mg}$ Spiro-OMeTAD, $28.8 \mu \mathrm{L}$ 4-tert-butylpyridine and $17.5 \mu \mathrm{L}$ of Li-bis (trifluorometha-nesulfonyl) imide solution $\left(520 \mathrm{mg} \cdot \mathrm{mL}^{-1}\right.$ in acetonitrile) were dissolved in $1 \mathrm{~mL}$ chlorobenzene to form a Spiro-OMeTAD solution, and the Spiro-OMeTAD layer was sequentially spin-coated at $3000 \mathrm{rpm}$ for $30 \mathrm{~s}$ so as to form the hole transfer layer. The gold electrode was then deposited on the Spiro-OMeTAD layer by vacuum evaporation to help form the entire perovskite device with an active area of $0.1 \mathrm{~cm}^{2}$. The structure of the whole device is shown in Figure 1a.

(a)

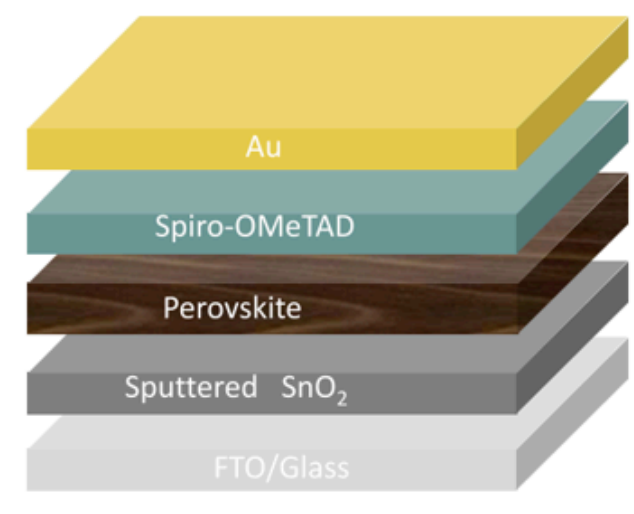

(b)

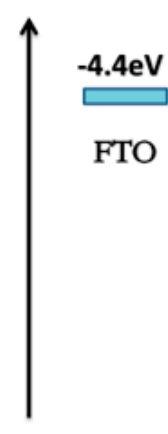

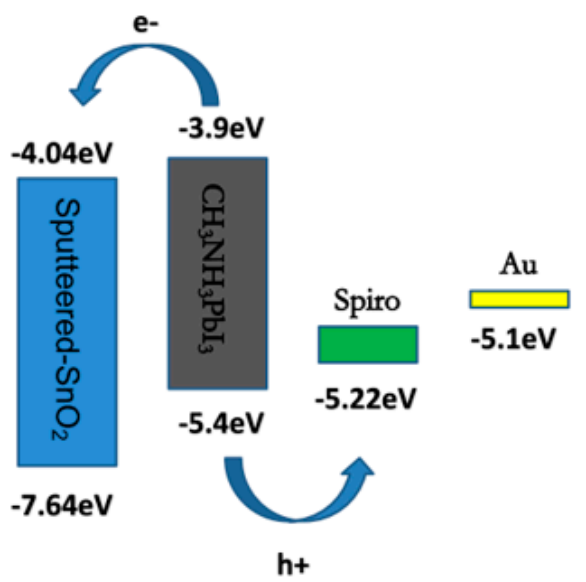

Figure 1. (a) Structure diagram and (b) band diagram of the device.

\subsection{Characterization}

Field-emission scanning electron microscopy (FESEM) images were obtained using a ZEISS SUPRA55 (Oberkochen, Germany). AFM figures were measured using a $300 \mathrm{HV}$ scanning force microscope (SEIKO, Tokyo, Japan). The photovoltaic performance of PSCs was recorded using a Keithley 4200 source meter under a one-sun AM 1.5G $\left(100 \mathrm{~mW} \cdot \mathrm{cm}^{-2}\right)$ illumination with a solar light simulator (Newport Oriel Sol3A Class AAA, 64023A Simulator, Mahwah, NJ, USA), which 
was calibrated using an NREL standard Si solar cell. The UV-Vis light absorption measurement was performed by using an ultraviolet-visible (UV-Vis) spectropho-tometer (Shimadzu UV-3101 PC, Kyoto, Japan). X-ray photoelectron spectroscopy (XPS) and ultraviolet photoelectron spectrum (UPS) measurements were conducted using an ESCALAB 250Xi (Thermo, Waltham, MA, USA) system. For XPS, the relevant parameters when measuring were as follows: Monochrome $\mathrm{Al} \mathrm{K} \alpha\left(h_{\mathrm{v}}=1486.6 \mathrm{eV}\right)$, power of $150 \mathrm{~W}$, a $500 \mu \mathrm{m}$ beam spot, a charge correction using contaminated carbon $(\mathrm{C} 1 \mathrm{~s}=284.8 \mathrm{eV})$ for correction, a constant analyzer pass energy $\left(E_{\mathrm{p}}\right)$, an energy narrow scan of $20 \mathrm{eV}$, and a vacuum of $1 \times 10^{-10} \mathrm{mba}$. External quantum efficiency (EQE) measurements were obtained on a Keithley 2000 multimeter (Cleveland, OH, USA) as a function of the wavelength from 350 to $800 \mathrm{~nm}$ on the basis of a Spectral Products DK240 monochromator. The PL spectra and fluorescence decay curves were taken out with a combined steady state fluorescence spectrometer (FLS980, Edinburgh, UK). The active area of the cell was $0.1 \mathrm{~cm}^{2}$. All samples were measured in air $\left(25^{\circ} \mathrm{C}\right)$.

\section{Results and Discussion}

The perovskite layer requires good absorption of light. It can be seen from the transmission spectrum in Figure 2a that the sputtered $\mathrm{SnO}_{2}$ film exhibited high light transmittance. In addition, the band gap of the sputtered $\mathrm{SnO}_{2}$ film was calculated from the transmission spectrum to be $3.79 \mathrm{eV}$, which is shown in the inset of Figure 2. The work function $(\phi)$ can be determined by the difference between the photon energy and the binding energy of the secondary cutoff edge. Combined with Figure $2 b$, we can get the conduction band and Fermi level. The position of the valence band was $-7.83 \mathrm{eV}$, respectively, and the position of the conduction band was $-4.04 \mathrm{eV}$. In addition, the Fermi level was $-4.74 \mathrm{eV}$. Figure $1 \mathrm{~b}$ shows the band diagram of a planar perovskite with $\mathrm{SnO}_{2}$ prepared by reactive sputtering as an electron transport layer. It can be seen that the $\mathrm{SnO}_{2}$ band structure prepared by reactive sputtering can completely transport the electron and hole properties of planar perovskite solar cells. Moreover, the valence band of the $\mathrm{SnO}_{2}$ prepared by reactive sputtering is lowered by $-5.4 \mathrm{eV}$. This shows that the sputtered tin oxide is suitable for the electron transport layer. The survey of XPS spectra in Figure 3a,b confirms the presence of $\mathrm{Sn}$ and $\mathrm{O}$ in reactive sputtered $\mathrm{SnO}_{2}$ film [34]. Compared with other literature, it can be seen that the Sn peak shifts, indicating the presence of oxygen defects in the reactive sputtered $\mathrm{SnO}_{2}$ [17]. The binding energies of the $\mathrm{Sn} 3 d_{5 / 2}$ and $\mathrm{Sn} 3 d_{3 / 2}$ peaks in the literature are 487.11 and $495.56 \mathrm{eV}$. However, the binding energies of tin oxide prepared by reactive sputtering are 495.14 and $486.69 \mathrm{eV}$, respectively. The tin oxide binding energy prepared by reactive sputtering is $0.42 \mathrm{eV}$ lower than that found in the literature. It shows that the tin oxide prepared by reactive sputtering contains a part of stannous fluoride, which is not completely tin oxide. In addition, we performed an EDS on the tin oxide layer and found that $\mathrm{Sn}: \mathrm{O}$ is 1:2. This shows that $\mathrm{SnO}_{2}$ prepared by reactive sputtering also has great potential. However, it can still be drawn that reactive sputtering of $\mathrm{SnO}_{2}$ is very suitable for the electron transport layer in planar.

The roughness of $\mathrm{SnO}_{2}$ prepared by reactive sputtering was detected by AFM, and blank FTO glass was used as a comparative sample. The measured value of the roughness is the average value of the three different areas on the surface of the sample. As shown in Figure 4a,b, the FTO glass without sputtering has a roughness of $31.8 \mathrm{~nm}$ and the roughness of the sample with sputtering is $30.2 \mathrm{~nm}$. It can be seen that the surface of the FTO glass has a lower roughness after sputtering. It can be inferred that the re-filling of the sputtered $\mathrm{SnO}_{2}$ nanoparticles onto the surface of the FTO glass reduces the surface roughness of the sample. In order to investigate the effect of this roughness variation on the perovskite layer, the surface morphology of the perovskite layer was observed on different substrates by FESEM. Figure 4c,d shows the FESEM morphology of a perovskite film deposited on the surface of FTO glass both with unsputtered and sputtered $\mathrm{SnO}_{2}$. It is obvious that the film deposited on the bare FTO by the perovskite film is rough and contains many large grains. However, the perovskite layer exhibits a flatter surface in the film of $\mathrm{SnO}_{2}$ prepared by reactive sputtering, and the grain size is more uniform with almost no large grain size. It can be concluded that the $\mathrm{SnO}_{2}$ film prepared by reactive sputtering has a positive effect on the subsequent perovskite layer deposition. Since one of the 
keys to a well-prepared perovskite solar cell is the interface, a good interface means a good device. On the one hand, reactive sputtering of the $\mathrm{SnO}_{2}$ film on the FTO surface effectively improves the surface, and the surface of the FTO is flatter, which provides a favorable position for the crystallization of the perovskite grains, making perovskite film smoother and more uniform. Therefore, $\mathrm{SnO}_{2}$ film prepared by reactive sputtering is very suitable for the electron transport layer material, as it effectively improves the crystallization of the perovskite layer, makes the perovskite smaller in size, and has a smoother surface, which reduces defects in interface contact. This kind of change is beneficial to improve the performance of the perovskite solar cell, which will be further proved by the photoelectric parameters of the device.
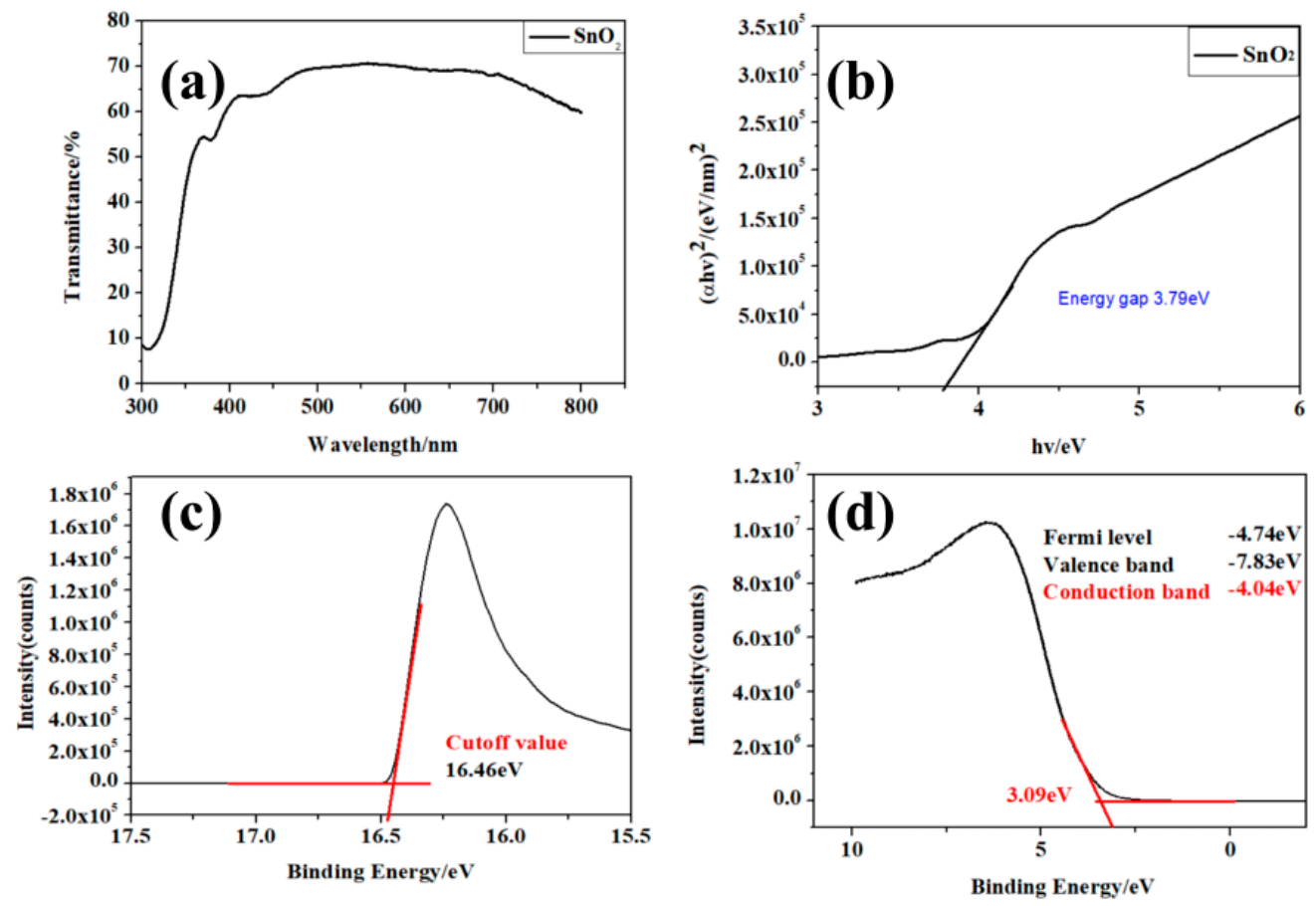

Figure 2. (a,b) Transmittance spectrum and Tauc plots of the $\mathrm{SnO}_{2}$ film sputtered on glass. (c,d) Ultraviolet photoelectron spectrum (UPS) of $\mathrm{SnO}_{2}$ film sputtered on silicon wafer.
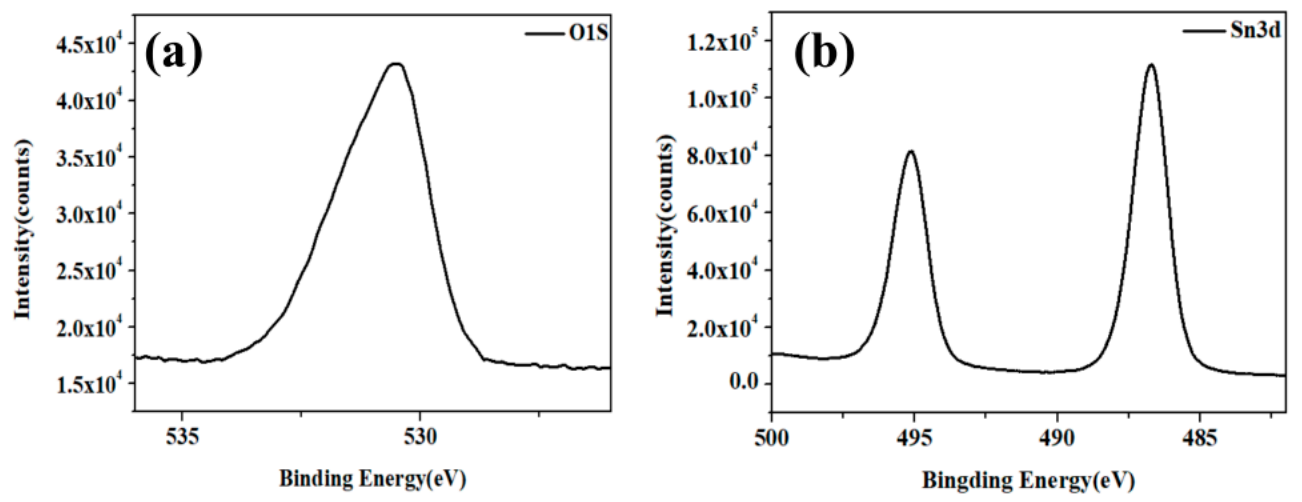

Figure 3. $(\mathbf{a}, \mathbf{b})$ The survey of XPS spectra of the $\mathrm{SnO}_{2}$ film on the FTO substrate. 

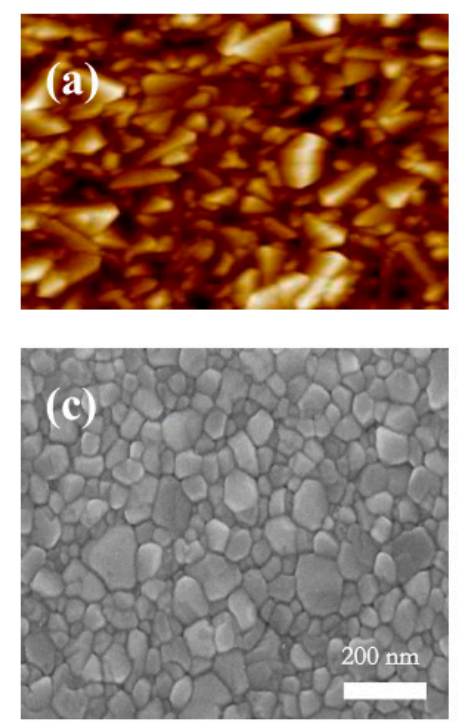
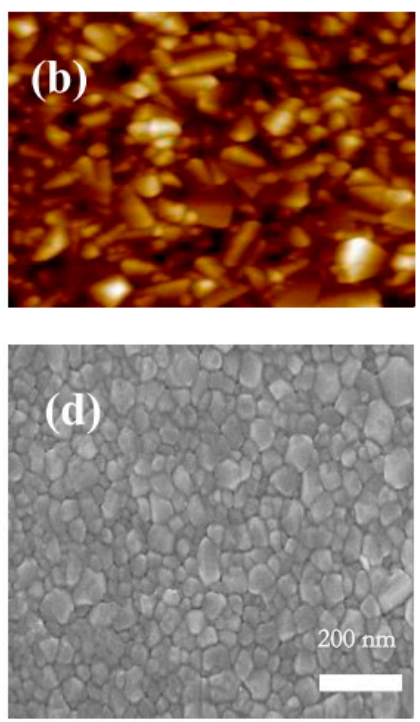

Figure 4. AFM images of surface morphology of FTO substrate without and with sputtered $\mathrm{SnO}_{2}$ film $(\mathbf{a}, \mathbf{b})$, and SEM images of perovskite films deposited on FTO substrate without and with reactive-sputtered $\mathrm{SnO}_{2}$ film $(\mathbf{c}, \mathbf{d})$.

The electron transport layer of planar perovskites, the deposition rate and sputtering time of $\mathrm{SnO}_{2}$ film prepared by reactive sputtering have a crucial influence on the optical and electrical properties of the device. $\mathrm{SnO}_{2}$ was deposited on FTO for $50 \mathrm{~min}$, and the thickness was determined by electron microscopy to be $30.5 \mathrm{~nm}$, thereby confirming the deposition rate of $0.61 \mathrm{~nm} / \mathrm{min}$. The thickness of the deposit varies linearly. Therefore, it is known that the deposition rate of $\mathrm{SnO}_{2}$ prepared by reactive sputtering is $0.61 \mathrm{~nm} / \mathrm{min}$. As a result, the thickness of sample RS-10, sample RS-20, and sample RS-30 was about 6.1, 12.2 and $18.3 \mathrm{~nm}$, respectively. Moreover, the effect of reactive sputtering time on the photoelectric properties of planar perovskites and the photoluminescence spectra of the corresponding samples were also investigated. The results are shown in Figure 5 and Table 1. Planar perovskite cells based on bare FTO have an efficiency of only $5.08 \%$ due to a poor short-circuit current $\left(\mathrm{J}_{\mathrm{sc}}\right)$ and fill factor (FF). After using $\mathrm{SnO}_{2}$ prepared by reactive sputtering as an electron transport layer, the performance of the entire device was greatly improved.
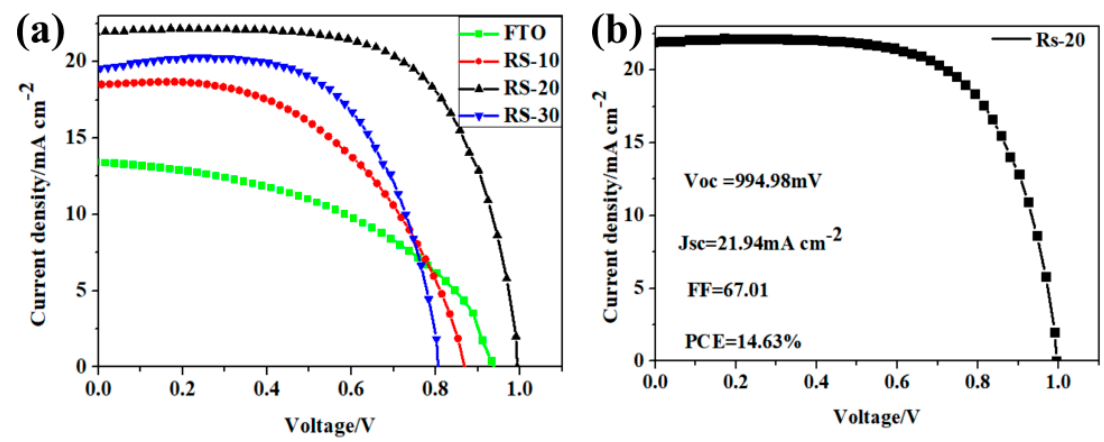

Figure 5. $J-V$ average curves of different planar perovskite solar cells (PSCs) (a,b) $J-V$ curve of the best planar PSC based on room temperature reactive sputtering of $\mathrm{SnO}_{2}$.

Table 1. Average photoelectric parameters of PSCs with different reaction sputtering times.

\begin{tabular}{cccccc}
\hline Sample & Sputtering Time (min) & Voc/V & $J_{\mathbf{s c}} / \mathbf{m A} \cdot \mathbf{c m}^{-\mathbf{2}}$ & $\mathbf{F F}(\%)$ & PCE (\%) \\
\hline FTO & 0 & 0.99 & 10.31 & 49 & 5.08 \\
RS-10 & 10 & 0.93 & 15.91 & 65 & 9.56 \\
RS-20 & 20 & 0.95 & 20.20 & 62 & 12.02 \\
RS-30 & 30 & 0.86 & 20.21 & 56 & 9.70 \\
\hline
\end{tabular}


The efficiency of the device reaches $12.02 \%$, the current reaches $20.20 \mathrm{~mA} \cdot \mathrm{cm}^{-2}$, and the filling factor reaches more than 65 . On the one hand, $\mathrm{SnO}_{2}$ prepared by reactive sputtering has a suitable band gap and energy level, which promotes electron transport and blocks holes. On the other hand, the perovskite layer becomes smoother on the $\mathrm{SnO}_{2}$ layer prepared by reactive sputtering compared to the bare FTO, improving $J_{\mathrm{sc}}$ and FF.

In contrast, the best reactive sputtering time is $20 \mathrm{~min}$, and the sample RS-20 shows the best device performance. The FF of sample RS-10 was much larger than the FF of sample FTO, but it is very close to the FF of sample RS-20, indicating that the length of reactive sputtering will have an impact on the coverage of $\mathrm{SnO}_{2}$ on the FTO surface. The longer the reactive sputtering time, the higher the coverage rate until the full coverage increases the thickness of $\mathrm{SnO}_{2}$ as the electron transport layer. When the sputtering time exceeds $20 \mathrm{~min}$, the tin oxide gradually becomes thicker, the resistance of the electron transport layer is increased, electrons are not efficiently transported, carrier recombination is increased, and the device performance deteriorates. $J_{\mathrm{sc}}$ first increases with the increase of sputtering time and then remains stable for a certain period of time, but as the sputtering time increases, $V_{\text {oc }}$ remains stable and then decreases within a certain range. It can be inferred that FF and $J_{\mathrm{sc}}$ keep increasing with the increase of $\mathrm{SnO}_{2}$ coverage. After complete coverage, the internal resistance increases as the thickness of $\mathrm{SnO}_{2}$ increase, but Voc decreases. As a result, $20 \mathrm{~min}$ is the optimum reaction sputtering time. In addition, it can be seen from the photoluminescence spectrum that when the perovskite layer is directly deposited on the surface of the FTO glass, it has the highest PL peak intensity, which indicates that the carrier recombination is the most serious. However, when $\mathrm{SnO}_{2}$ film of RS-10 is added, the peak intensity is found to be significantly weakened. Therefore, $\mathrm{SnO}_{2}$ can effectively suppress the recombination of carriers. However, due to the short time, the thinner thickness may not completely cover the FTO layer, which results in the peak strength to not be minimal. When the time reaches $20 \mathrm{~min}$, the peak intensity is minimized, with the smallest carrier recombination as well as the highest photoelectric conversion efficiency being achieved. As time continues to $30 \mathrm{~min}$, it can be seen that the PL peak will become larger, which indicates that the charge recombination is also increasing, thereby affecting the performance of the entire device. Therefore, the optimal reaction sputtering time is $20 \mathrm{~min}$.

It can be seen that the main photoelectric properties of the reactive-sputtered $\mathrm{SnO}_{2}$ of the planar perovskite are short-circuit current and fill factor. Therefore, we have studied the external quantum efficiency (EQE) of a planar perovskite with $\mathrm{SnO}_{2}$ as the electron transport layer and with no $\mathrm{SnO}_{2}$, as shown in Figure $6 \mathrm{a}$. The $J_{\mathrm{sc}}$ of sample RS-20 was calculated from the EQE curve to be 20.07 $\mathrm{mA} \cdot \mathrm{cm}^{-2}$, which is close to the experiment value. It can also be seen that the $\mathrm{SnO}_{2} \mathrm{ETL}$ prepared by reactive sputtering effectively improves the EQE curve intensity and range of the PSCs. The reactive sputter-deposited $\mathrm{SnO}_{2}$ has an impact on the EQE performance of the device in two aspects. On the one hand, the deposition of $\mathrm{SnO}_{2}$ ETLs improves the deposition of the perovskite layer as well as the light absorption performance of the device. On the other hand, reactive sputter-deposited $\mathrm{SnO}_{2}$ acts as an interfacial layer between the perovskite layer and the FTO glass substrate, thereby greatly improving the carrier transport and hole-blocking properties of the device. It can be seen from Figure $7 \mathrm{c}$ that the carrier transport of the perovskite film containing the tin oxide layer is faster than that of the perovskite layer without the tin oxide layer, further demonstrating that the tin oxide prepared by reactive sputtering is suitable as the electron transport layer. This is consistent with the results of PL. In addition, the CV curve of the dark state CV curve and the illumination condition were also consistent. We first examined the $\mathrm{CV}$ curve, then the dark $\mathrm{CV}$ curve, which may have some effect.

This proves that the $\mathrm{SnO}_{2}$ film prepared by reactive sputtering at room temperature is feasible as an ETL of a perovskite device. In addition, the optimal deposition efficiency of the perovskite layer was optimized by optimizing the reactive sputtering conditions, and the best photoelectric efficiency was obtained in sample RS-20, as shown in Figure 5b. The parameters are as follows: $V_{\mathrm{oc}}=994.98 \mathrm{mV}, \mathrm{Jsc}=21.94 \mathrm{~mA} \cdot \mathrm{cm}^{-2}, \mathrm{FF}=67.01$, and $\mathrm{PCE}=14.63 \%$. In Figure 8, we show a histogram of the performance parameters of 30 devices, which shows that we have good repeatability. 
(a)
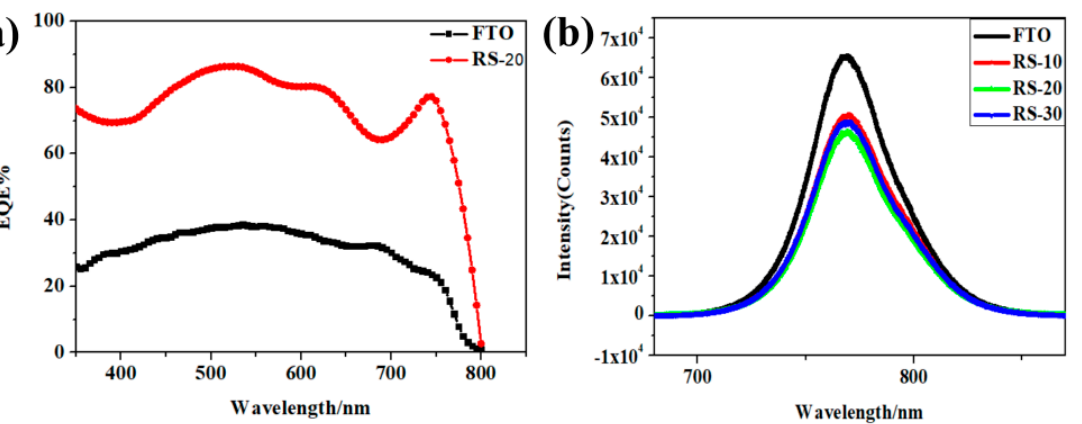

Figure 6. (a) External quantum efficiency (EQE) curves of different planar PSCs and (b) the corresponding photoluminescence spectra of the samples.
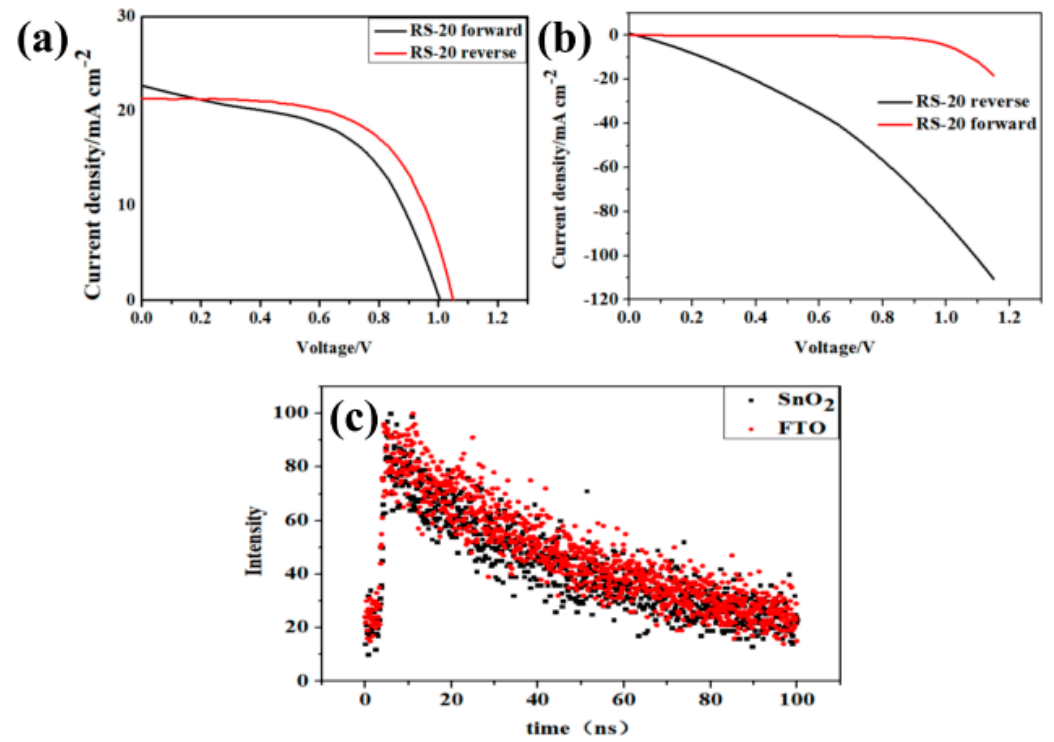

Figure 7. (a) Forward and reverse bias $J-V$ characteristics of the RS-20; (b) $J-V$ characteristics of the RS-20 under dark illumination; (c) Time resolved photoluminescence (TRPL) curve of the FTO substrate and the sputtered tin oxide substrate.
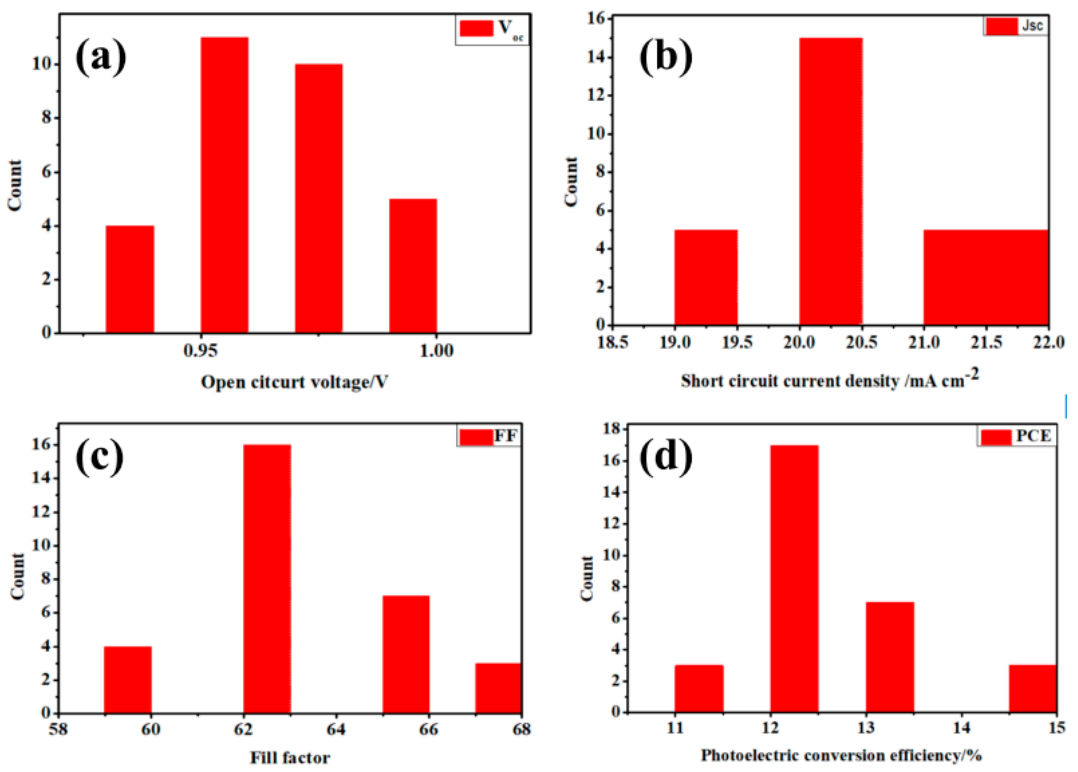

Figure 8. Histograms of (a) Voc, (b) Jsc, (c) FF, and (d) PCE of 30 PSCs based on $\mathrm{SnO}_{2} \mathrm{HBL}$ reactive sputtering. 


\section{Conclusions}

In general, this work illustrates the potential of reactive sputtering to produce $\mathrm{SnO}_{2}$ as a planar perovskite electron transport layer at room temperature. $\mathrm{SnO}_{2}$ film prepared by reactive sputtering has a high transmittance and a suitable energy band structure. The ultra-thin $\mathrm{SnO}_{2}$ improves the roughness of the perovskite layer, thereby effectively strengthening the planar perovskite into electrons and air. In addition, the reactive sputtering preparation of $\mathrm{SnO}_{2}$ has good repeatability. Moreover, the highest efficiency of perovskite prepared by reactive sputtering based on $\mathrm{SnO}_{2}$ reached $14.63 \%$, which will open new ideas for large-area applications and commercial applications of perovskites. This is far from the limit of reactive tin oxide preparation, and various parameters have yet to be improved, thereby helping to improve the application capacity of perovskites.

Author Contributions: Conceptualization, W.S. and R.M.; Methodology, W.S.; Software, S.W., S.L., Y.Z., X.M., and C.D.; Formal Analysis, S.W.; Investigation, W.S.; Resources, C.W.; Data Curation, W.S.; Writing-Original Draft Preparation, W.S.; Writing-Review and Editing, W.S.; Visualization, S.W.; Supervision, R.M.; Project Administration, C.W.; Funding Acquisition, C.W.

Funding: This research was funded by the Fundamental Research Funds for the Central Universities, No. 230201606500078. This research was funded by the National Natural Science Foundation of China, Nos. U1302274 and 51674026.

Conflicts of Interest: The authors declare no conflict of interest.

\section{References}

1. Kojima, A.; Teshima, K.; Shirai, Y.; Miyasaka, T. Organometal halide perovskites as visible-light sensitizers for photovoltaic cells. J. Am. Chem. Soc. 2009, 131, 6050-6051. [CrossRef]

2. Bai, Y.; Meng, X.; Yang, S. Interface engineering for highly efficient and stable planar p-i-n perovskite solar cells. Adv. Energy Mater. 2018, 8, 1701883. [CrossRef]

3. Jeon, N.J.; Na, H.; Jung, E.H.; Yang, T.-Y.; Lee, Y.G.; Kim, G.; Shin, H.-W.; Seok, S.I.; Lee, J.; Seo, J. A fluorene-terminated hole-transporting material for highly efficient and stable perovskite solar cells. Nat. Energy 2018, 3, 682-689. [CrossRef]

4. Yang, W.S.; Park, B.; Jung, E.H.; Jeon, N.J.; Kim, Y.C.; Lee, D.U.; Shin, S.S.; Seo, J.; Kim, E.K.; Noh, J.H.; et al. Iodide management in formamidinium-lead-halide-based perovskite layers for efficient solar cells. Science 2017, 356, 1376-1379. [CrossRef] [PubMed]

5. Saliba, M.; Matsui, T.; Seo, J.Y.; Domanski, K.; Correa-Baena, J.P.; Nazeeruddin, M.K.; Zakeeruddin, S.M.; Tress, W.; Abate, A.; Hagfeldt, A.; et al. Cesium-containing triple cation perovskite solar cells: Improved stability, reproducibility and high efficiency. Energy Environ. Sci. 2016, 9, 1989-1997. [CrossRef] [PubMed]

6. Tao, H.; Ma, Z.; Yang, G.; Wang, H.; Long, H.; Zhao, H.; Qin, P.; Fang, G. Room-temperature processed tin oxide thin film as effective hole blocking layer for planar perovskite solar cells. Appl. Surf. Sci. 2018, 434, 1336-1343. [CrossRef]

7. Edri, E.; Kirmayer, S.; Henning, A.; Mukhopadhyay, S.; Gartsman, K.; Rosenwaks, Y.; Hodes, G.; Cahen, D. Why lead methylammonium tri-iodide perovskite-based solar cells require a mesoporous electron transporting scaffold (but not necessarily a hole conductor). Nano Lett. 2014, 14, 1000-1004. [CrossRef] [PubMed]

8. Shin, S.S.; Yeom, E.J.; Yang, W.S.; Hur, S.; Kim, M.G.; Im, J.; Seo, J.; Noh, J.H.; Seok, S.I. Colloidally prepared La-doped $\mathrm{BaSnO}_{3}$ electrodes for efficient, photostable perovskite solar cells. Science 2017, 356, 167-171. [CrossRef] [PubMed]

9. Qin, M.; Ma, J.; Ke, W.; Qin, P.; Lei, H.; Tao, H.; Zheng, X.; Xiong, L.; Liu, Q.; Chen, Z.; et al. Perovskite solar cells based on low-temperature processed indium oxide electron selective layers. ACS Appl. Mater. Interfaces 2016, 8, 8460-8466. [CrossRef]

10. Wang, K.; Shi, Y.; Dong, Q.; Li, Y.; Wang, S.; Yu, X.; Wu, M.; Ma, T. Low-temperature and solution-processed amorphous $\mathrm{WO}_{X}$ as electron-selective layer for perovskite solar cells. J Phys. Chem. Lett. 2015, 6, 755-759. [CrossRef] [PubMed]

11. Zhang, P.; Wu, J.; Zhang, T.; Wang, Y.; Liu, D.; Chen, H.; Ji, L.; Liu, C.; Ahmad, W.; Chen, Z.D.; et al. Perovskite solar cells with ZnO electron-transporting materials. Adv. Mater. 2018, 30, 1703737. [CrossRef] 
12. Yang, Z.; Xie, J.; Arivazhagan, V.; Xiao, K.; Qiang, Y.; Huang, K.; Hu, M.; Cui, C.; Yu, X.; Yang, D. Efficient and highly light stable planar perovskite solar cells with graphene quantum dots doped PCBM electron transport layer. Nano Energy 2017, 40, 345-351. [CrossRef]

13. Xiong, L.; Guo, Y.; Wen, J.; Liu, H.; Yang, G.; Qin, P.; Fang, G. Review on the application of $\mathrm{SnO}_{2}$ in perovskite solar cells. Adv. Funct. Mater. 2018, 28, 1802757. [CrossRef]

14. Yang, G.; Chen, C.; Yao, F.; Chen, Z.; Zhang, Q.; Zheng, X.; Ma, J.; Lei, H.; Qin, P.; Xiong, L.; et al. Effective carrier-concentration tuning of $\mathrm{SnO}_{2}$ quantum dot electron-selective layers for high-performance planar perovskite solar cells. Adv. Mater. 2018, 30, 1706023. [CrossRef] [PubMed]

15. Yang, D.; Yang, R.; Wang, K.; Wu, C.; Zhu, X.; Feng, J.; Ren, X.; Fang, G.; Priya, S.; Liu, S. High efficiency planar-type perovskite solar cells with negligible hysteresis using EDTA-complexed $\mathrm{SnO}_{2}$. Nat. Commun. 2018, 9, 3239. [CrossRef]

16. Gao, C.; Yuan, S.; Cao, B.; Yu, J. $\mathrm{SnO}_{2}$ nanotube arrays grown via an in situ template-etching strategy for effective and stable perovskite solar cells. Chem. Eng. J. 2017, 325, 378-385. [CrossRef]

17. Ke, W.; Fang, G.; Liu, Q.; Xiong, L.; Qin, P.; Tao, H.; Wang, J.; Lei, H.; Li, B.; Wan, J.; et al. Low-temperature solution-processed tin oxide as an alternative electron transporting layer for efficient perovskite solar cells. J. Am. Chem. Soc. 2015, 137, 6730-6733. [CrossRef]

18. Gholipour, S.; Correa-Baena, J.-P.; Domanski, K.; Matsui, T.; Steier, L.; Giordano, F.; Tajabadi, F.; Tress, W.; Saliba, M.; Abate, A.; et al. Highly efficient and stable perovskite solar cells based on a low-cost carbon cloth. Adv. Energy Mater. 2016, 6, 1601116. [CrossRef]

19. Chen, J.-Y.; Chueh, C.-C.; Zhu, Z.; Chen, W.-C.; Jen, A.K.-Y. Low-temperature electrodeposited crystalline $\mathrm{SnO}_{2}$ as an efficient electron-transporting layer for conventional perovskite solar cells. Sol. Energy Mater. Sol. Cells 2017, 164, 47-55. [CrossRef]

20. Jiang, Q.; Zhang, L.; Wang, H.; Yang, X.; Meng, J.; Liu, H.; Yin, Z.; Wu, J.; Zhang, X.; You, J. Enhanced electron extraction using $\mathrm{SnO}_{2}$ for high-efficiency planar-structure $\mathrm{HC}\left(\mathrm{NH}_{2}\right)_{2} \mathrm{PbI}_{3}$-based perovskite solar cells. Nat. Energy 2016, 2, 16177. [CrossRef]

21. Chen, C.; Cheng, Y.; Dai, Q.; Song, H. Radio frequency magnetron sputtering deposition of $\mathrm{TiO}_{2}$ thin films and their perovskite solar cell applications. Sci. Rep. 2015, 5, 17684. [CrossRef]

22. Ge, S.; Xu, H.; Wang, W.; Cao, R.; Wu, Y.; Xu, W.; Zhu, J.; Xue, F.; Hong, F.; Xu, R.; et al. The improvement of open circuit voltage by the sputtered $\mathrm{TiO}_{2}$ layer for efficient perovskite solar cell. Vacuum 2016, 128, 91-98. [CrossRef]

23. Tao, H.; Ke, W.; Wang, J.; Liu, Q.; Wan, J.; Yang, G.; Fang, G. Perovskite solar cell based on network nanoporous layer consisted of $\mathrm{TiO}_{2}$ nanowires and its interface optimization. J. Power Sources 2015, 290, 144-152. [CrossRef]

24. Lai, W.-C.; Lin, K.-W.; Guo, T.-F.; Chen, P.; Wang, Y.-T. Conversion efficiency improvement of inverted $\mathrm{CH}_{3} \mathrm{NH}_{3} \mathrm{PbI}_{3}$ perovskite solar cells with room temperature sputtered $\mathrm{ZnO}$ by adding the $\mathrm{C}_{60}$ interlayer. Appl. Phys. Lett. 2015, 107, 253301. [CrossRef]

25. Mali, S.S.; Hong, C.K.; Inamdar, A.I.; Im, H.; Shim, S.E. Efficient planar n-i-p type heterojunction flexible perovskite solar cells with sputtered $\mathrm{TiO}_{2}$ electron transporting layers. Nanoscale 2017, 9, 3095-3104. [CrossRef] [PubMed]

26. Rajmohan, G.; Huang, F.; D'Agostino, R.; Du Plessis, J.; Dai, X. Low temperature reactively sputtered crystalline $\mathrm{TiO}_{2}$ thin film as effective blocking layer for perovskite solar cells. Thin Solid Films 2017, 636, 307-313. [CrossRef]

27. Di Giulio, M.; Micocci, G.; Serra, A.; Tepore, A.; Rella, R.; Siciliano, P. $\mathrm{SnO}_{2}$ thin films for gas sensor prepared by RF reactive sputtering. Sens. Actuators B 1995, 25, 465-468. [CrossRef]

28. Qiu, L.; Liu, Z.; Ono, L.K.; Jiang, Y.; Son, D.Y.; Hawash, Z.; He, S.; Qi, Y. Scalable fabrication of stable high efficiency perovskite solar cells and modules utilizing room temperature sputtered $\mathrm{SnO}_{2}$ electron transport layer. Adv. Funct. Mater. 2018, 1806779. [CrossRef]

29. Nishihara, Y.; Chikamatsu, M.; Kazaoui, S.; Miyadera, T.; Yoshida, Y. Influence of $\mathrm{O}_{2}$ plasma treatment on $\mathrm{NiO}_{x}$ layer in perovskite solar cells. JPn. J. Appl. Phys. 2018, 57, 04FS07. [CrossRef]

30. Xiao, Z.G.; Zeng, X.S.; Guo, H.M.; Zhao, Z.F.; Shi, T.F.; Wang, Y.Q. Preparation of NiO transparent conductive film and its application in polymer solar cells. Acta Phys. Sin. 2012, 61, 26379. (In Chinese) 
31. Raifuku, I.; Ishikawa, Y.; Bourgeteau, T.; Bonnassieux, Y.; I Cabarrocas, P.R.; Uraoka, Y. Fabrication of perovskite solar cells using sputter-processed $\mathrm{CH}_{3} \mathrm{NH}_{3} \mathrm{PbI}_{3}$ films. Appl. Phys. Express 2017, 10, 94101. [CrossRef]

32. Wang, S.; Liu, B.; Zhu, Y.; Ma, Z.; Liu, B.; Miao, X.; Ma, R.; Wang, C. Enhanced performance of $\mathrm{TiO}_{2}$-based perovskite solar cells with Ru-doped $\mathrm{TiO}_{2}$ electron transport layer. Sol. Energy 2018, 169, 335-342. [CrossRef]

33. Wang, S.; Zhu, Y.; Sun, W.; Miao, X.; Ma, Z.; Yang, C.; Liu, B.; Li, S.; Ma, R.; Wang, C. Large guanidinium cation enhance photovoltage for perovskite solar cells via solution-processed secondary growth technique. Sol. Energy 2018, 176, 118-125. [CrossRef]

34. Yang, G.; Lei, H.; Tao, H.; Zheng, X.; Ma, J.; Liu, Q.; Ke, W.; Chen, Z.; Xiong, L.; Qin, P.; Chen, Z. Reducing hysteresis and enhancing performance of perovskite solar cells using low-temperature processed Y-doped $\mathrm{SnO}_{2}$ nanosheets as electron selective layers. Small 2017, 13, 1601769. [CrossRef]

(C) 2019 by the authors. Licensee MDPI, Basel, Switzerland. This article is an open access article distributed under the terms and conditions of the Creative Commons Attribution (CC BY) license (http://creativecommons.org/licenses/by/4.0/). 